\title{
How good is your defibrillation technique?
}

\author{
Daniel M Sado BM BSc ${ }^{1} \quad$ Charles D Deakin MD FRCA ${ }^{2}$
}

J R Soc Med 2005;98:3-6

In 1956, a patient in ventricular fibrillation (VF) was successfully treated via externally applied electricity. ${ }^{1}$ The history of human defibrillation, which is still the only effective means of cardioverting VF back into sinus rhythm, began here. By 1962, electric shock had also been found effective in atrial fibrillation and atrial flutter. ${ }^{2}$

In August 2000 the International Liaison Committee on Resuscitation (ILCOR) published evidence-based guidelines for adult and paediatric life support. ${ }^{3}$ All the UK training courses on advanced life support are now based on the ILCOR guidelines; yet, in this document of over 400 pages, the defibrillation section is only 4 pages long. This is partly because the topic had been under-researched. New information has emerged since 2000. Our own group has taken a special interest in the defibrillation technique used by hospital practitioners and how it could be improved.

Survival to discharge from in-hospital cardiac arrest in the UK is still, at best, only $17 \%$ in a monitored area of the hospital such as a coronary care unit. ${ }^{4}$ It is considerably worse on general hospital wards. The most important factor in determining whether defibrillation will be successful is the time that elapses before delivery of the first shock. ${ }^{5}$ For every minute post-arrest, the chances of cardioversion decrease by as much as $10 \% .^{3}$ Many defibrillators in hospitals now have an automated facility, so that a nurse suspecting a cardiac arrest can connect the patient to the machine via two pads; ${ }^{6}$ the device analyses the cardiac rhythm and delivers a shock if appropriate. A study in hospital inpatients has shown that use of the automated facility on new biphasic defibrillators can yield a 2.6-fold increase in survival post-arrest. ${ }^{7}$ All nurses should therefore be trained to use an automated defibrillator if one is available on their ward. ${ }^{8}$

Recently, there have been two major developments in defibrillator technology. One is the emergence of pads made of flexible conductive material. ${ }^{9}$ Our group found that the transthoracic impedance (TTI) to current flow created by use of these pads is the same as that with paddles. ${ }^{10}$ At present there is uncertainty as to which method is preferable. The second advance concerns the

1Department of Oncology, Poole General Hospital, Poole BH15 2JB;

${ }^{2}$ Department of Cardiothoracic Anaesthesia, Southampton General Hospital,

Southampton SO16 6YD, UK

Correspondence to: Dr Dan Sado

E-mail: dan_sado@yahoo.com waveform used for defibrillation. Originally, the waveform created by defibrillators was monophasic but over the last ten years the biphasic waveform has taken over and nearly all new models use this technology ${ }^{11}$ (Figure 1). The relative merits of these two waveforms are beyond the scope of this article. In summary, a biphasic shock of 150 joules is far more likely than a monophasic shock of either 200 or 360 joules to convert VF; yet, so far, no study has shown a survival advantage for the biphasic method. ${ }^{12}$

Successful defibrillation depends on delivery of the shock to a critical mass of myocardium ${ }^{13}$ and this in turn depends on the transthoracic current flow (TCF) achieved. If the TCF is too low, defibrillation will fail; if it is too high the result may be myocardial cell damage and even necrosis. On the evidence of post-mortem studies and troponin measurement after defibrillation, necrosis is not a common result of multiple shock delivery. ${ }^{14,15}$ The most likely reason for failure is a TCF that is too low.

TCF is determined by the energy selected and the TTI: ${ }^{16}$

$\mathrm{TCF}=\sqrt{ }($ energy selected $/ \mathrm{TTI})$

Clearly a low TTI will result in a high TCF. Numerous studies have shown that a high TTI will decrease the chances of delivering a successful shock to the patient; ${ }^{17-19}$ therefore, during defibrillation, TTI has to be reduced as far as possible. Some contributory factors, such as thoracic

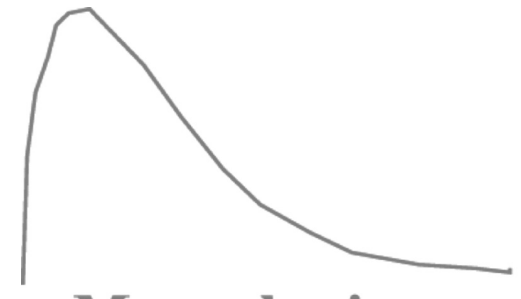

Monophasic

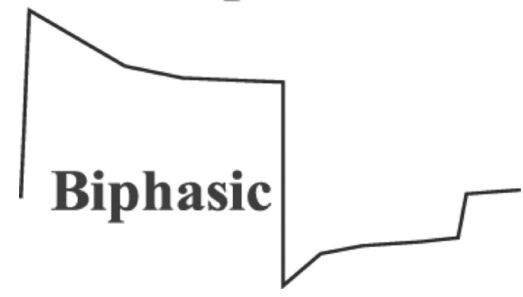

Figure 1 Monophasic and biphasic waveforms used by defibrillators 
size, are intrinsic and cannot be altered; but extrinsic factors include paddle force, presence of chest hair, use of an electrical coupling agent, ${ }^{20}$ the size of the paddles (larger electrodes have a lower impedance but when excessively large can result in less $\mathrm{TCF}^{18}$ ), the number of shocks delivered ${ }^{21}$ and paddle position. This article focuses on techniques for minimizing TTI.

\section{PAD/PADDLE PLACEMENT}

According to the ILCOR guidelines, the sternal paddle should be placed 'just to the right of the upper sternal border below the clavicle' and the apical paddle 'to the left of the nipple with the centre of the electrode in the midaxillary line'. ${ }^{3}$ In a survey of 101 doctors we found that only $22 \%$ placed the apical paddle in this position with the majority placing it too superomedially, ${ }^{22}$ a Finnish group made similar observations in 136 healthcare professionals. ${ }^{23}$ Whether these deviations from guidelines decrease the success rates is uncertain. No group has yet elicited the pathways taken by defibrillator current through the human body. In theory, a paddle position that is too superomedial means that less current will traverse the myocardium.

During the gel pad placement study we noticed that about $50 \%$ of doctors placed the rectangular apical paddle vertically upwards, pointing towards the left armpit (Figure 2). The other $50 \%$ placed it in a horizontal position across the chest (Figure 3). The present ILCOR guidelines do not specify which orientation should be used for defibrillation. We hypothesized that, with the paddle method for defibrillation, it would be more difficult to get good skin contact across the curved chest wall with the horizontal orientation, and in a small study this proved to be the case. ${ }^{24}$ When $60 \mathrm{~N}$ (the median force used by defibrillator operators in clinical practice ${ }^{25}$ ) is applied to both paddles, the resulting TTI is $5 \%$ greater with the horizontal

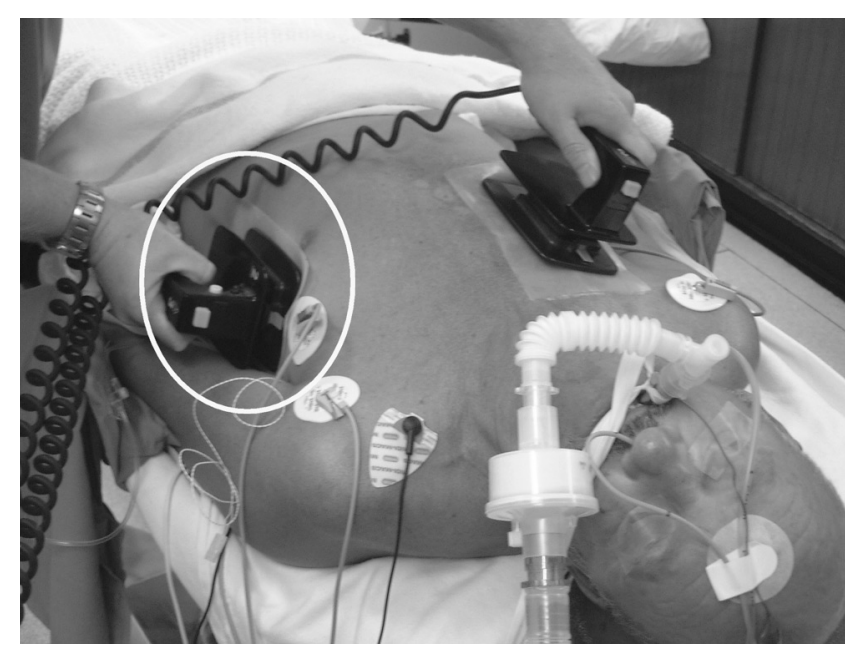

Figure 2 Apical gel pad / paddle (in circle) in vertical position orientation. Thus, if paddles are used, we recommend a vertical orientation. This question has not been addressed in relation to pads. We would expect their flexibility to allow better electrode/skin contact across the curved chest wall; however, in the absence of any evidence to the contrary, we advise vertical orientation for this method as well.

\section{PADDLE FORCE}

As increasing force is applied to defibrillator paddles, the better paddle/skin contact and expulsion of air from the lungs should decrease the TTI. ${ }^{26}$ In a study of forces used in clinical practice ${ }^{25}$ operators applied a median of $60 \mathrm{~N}$ to each paddle. This is equivalent to the force created by placing six one-litre bags of water on the chest. The 1992 European Resuscitation Council (ERC) guidelines recommended $120 \mathrm{~N}$ applied to each paddle. ${ }^{27}$ We asked 50 operators to press with $120 \mathrm{~N}$ on two defibrillator paddles placed on a resuscitation mannequin; ${ }^{28}$ only 7 were physically able to attain this pressure. The more recent ILCOR guidelines simply specify 'firm force' ${ }^{3}$ Neither of these recommendations was evidence-based. Studying the relation between paddle force and TTI, ${ }^{29}$ we found that $95 \%$ of the decline from $5 \mathrm{~N}$ to $120 \mathrm{~N}$ could be achieved with $80 \mathrm{~N}$ (Figure 4). In a subsequent investigation, ${ }^{30} 19 \%$ of this decrease in TTI proved to be due to expulsion of air from the lungs and $81 \%$ probably due to better contact at the paddle/skin interface. This observation has implications for the use of pads: since no force is applied to these, the extra 19\% drop in TTI caused by expulsion of air will not be attained. One group has shown, in pigs, that application of force to pads via non-conductive material does further decrease TTI. ${ }^{31}$

Our own investigations indicated that $80 \%$ of operators were physically capable of pressing with $80 \mathrm{~N}$ but only $14 \%$

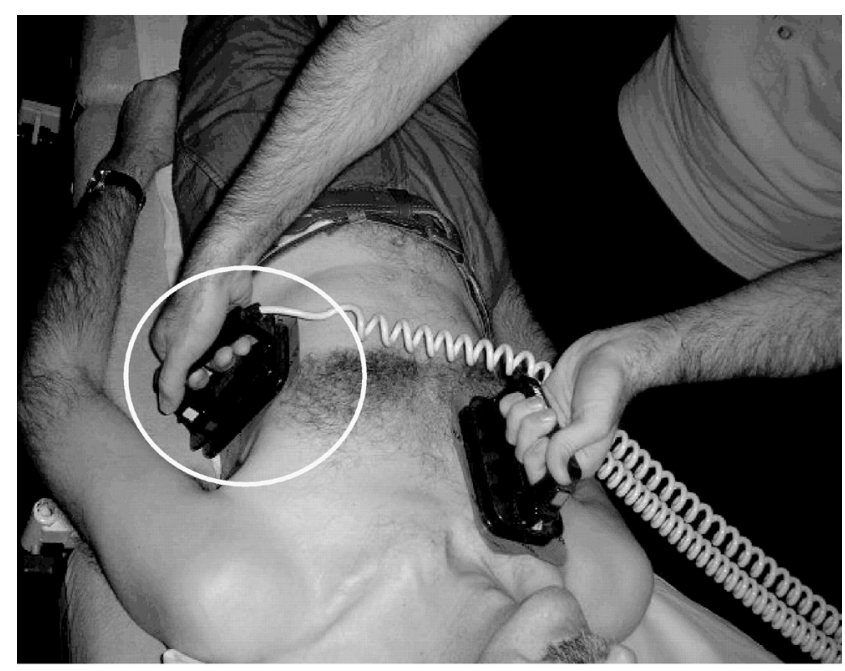

Figure 3 Apical gel pad / paddle (in circle) in horizontal position 


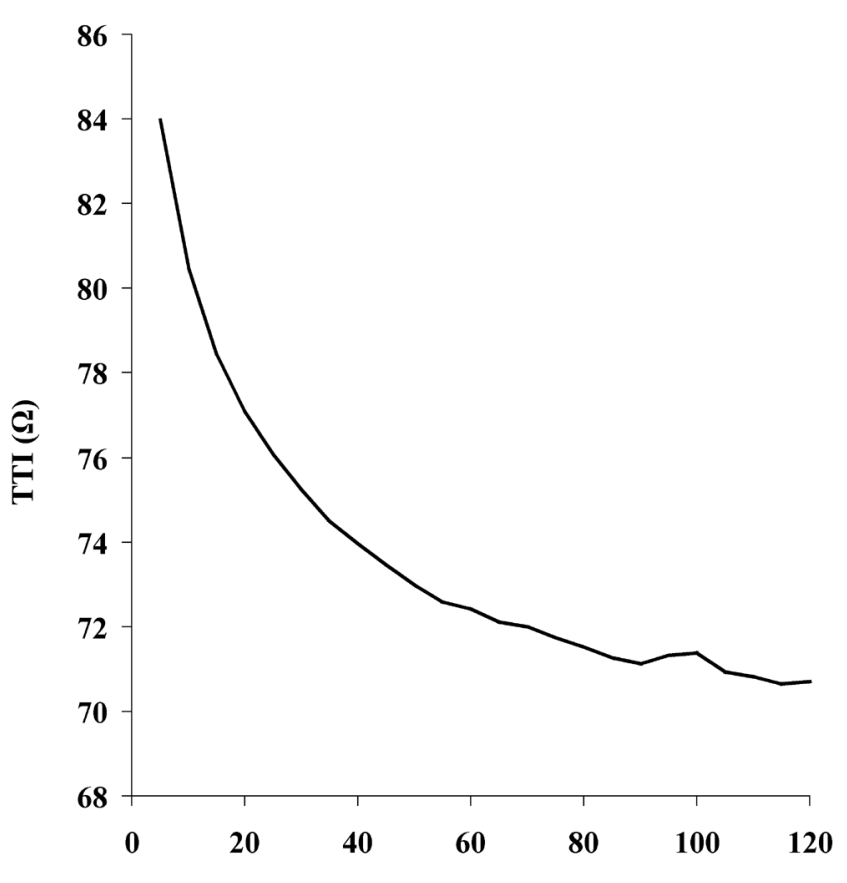

Average force applied to both paddles (N)

Figure 4 Relation of paddle force to transthoracic impedance (TTI) [from Ref 29 by courtesy of the American Journal of Cardiology]

at $120 \mathrm{~N} .{ }^{28}$ At present over $50 \%$ of operators are not pressing hard enough on the paddles when defibrillating and $80 \mathrm{~N}$ seems a reasonable force to aim for. ${ }^{25}$

It would help if training rooms were equipped with paddles instrumented to measure force. For those who do not know what constitutes $80 \mathrm{~N}$ we recommend pressing down as hard as possible.

\section{CHEST HAIR}

In 2000 Bissing et al..$^{31}$ examined the effect of chest hair on the TTI when self-adhesive pads were used. Removal of chest hair from hirsute patients decreased the TTI by 35\%, so they recommended chest shaving in such patients before defibrillation. We conducted a similar study looking at the effect of chest hair with the gel pad/paddle method. ${ }^{31}$ Might an increase in paddle force in itself be sufficient to overcome the additional TTI? The answer was that it only partly did. At $60 \mathrm{~N}$ chest hair caused a $10.4 \%$ increase in TTI whereas at $120 \mathrm{~N}$ it caused only a $7.1 \%$ increase. We also found that the more hirsute the chest, the greater the effect on TTI produced by shaving.

From these studies, it seems that the effect of chest hair on TTI will be much greater with pads than with paddles. There was, however, one confounding factor in the selfadhesive pad study. The apical gel pad was placed directly over the cardiac apex and not in the mid-axillary line as specified by the ILCOR guidelines. In our experience, patients who are hairy over their cardiac apex are usually hairless in the mid-axillary line. Thus incorrect pad position would exaggerate the effect of hair on TTI since hair would have been present under both pads rather than just one.

Whatever method of defibrillation is used, chest hair increases TTI and decreases the chance of successful shock delivery. In addition, very high impedance at the paddle/ skin interface puts the patient at risk of skin burns. The ILCOR guidelines therefore recommend shaving of the hirsute chest before defibrillation. The counter-argument is that shaving takes time and the main determinant of shock success is time to first shock. In hirsute patients who have had a cardiac arrest or are at high risk, we recommend chest shaving in the area where the defibrillation pads or paddles would be placed; in case of an arrest, no time would then be lost in shaving.

\section{CONCLUSIONS}

At present, there is no research showing how much of an impact each ohm decrease in TTI will have on patient outcome. We do know, however, that a high TTI decreases the chances of successful shock delivery and we suspect that many defibrillation failures are due to insufficient transthoracic current flow. ${ }^{15-20}$ Most healthcare workers are not achieving optimal TTI during defibrillation. There is now good evidence that use of a coupling agent, chest hair removal, placement of the apical paddle in a vertical orientation lateral to the nipple in the mid-axillary line and application of at least $80 \mathrm{~N}$ of force are all measures that help minimize the TTI. ${ }^{21,24,29,33}$ Whether self-adhesive pads or defibrillator paddles should be used is still an area of debate. In the hands of skilled operators the paddle method is preferable because force can be applied. This is of particular benefit in hirsute men. ${ }^{30,31}$ In non-hirsute persons, the TTI produced by the two methods does not differ importantly. ${ }^{9}$ Self-adhesive pads are preferable for use by less experienced operators and are ideal for the automated devices used in the community. They also allow the automated mode to be used by ward nurses before the cardiac arrest team arrives. Box 1 summarizes the main points of this article according to our ASAP mnemonic.

\section{Box 1 The ASAP for defibrillation}

Axilla pad/paddle position — lateral to nipple in midaxillary line in vertical orientation

$\mathbf{S}_{\text {have }}$ - a hirsute chest before defibrillation

Apply correct paddle force - at least $80 \mathrm{~N}$

$\mathbf{P}_{\text {unctuality saves lives }}$ 


\section{REFERENCES}

1 Lown B, Amarasingham R, Neuman J. New method for terminating cardiac arrhythmias: use of synchronised capacitor discharge. JAMA 1962;182:548-55

2 Lown B. Electrical reversion of cardiac arrhythmias. Br Heart J 1967; 29:469-89

3 International Resuscitation Council. Guidelines. Resuscitation 2000;46: $109-13$

4 Gwinnutt CL, Columb M, Harris R. Outcome after cardiac arrest in adults in UK hospitals: effect of the 1997 guidelines. Resuscitation 2000; 47: $125-35$

5 Spearpoint KG, McLean CP, Zideman DA. Early defibrillation and the chain of survival in 'in-hospital' adult cardiac arrest; minutes count. Resuscitation 2000;44:165-9

6 Jaffa A, Landau WM, Wetzel RD. Automated external defibrillators. N Engl J Med 2001;344:771-3

7 Zafari AM, Zarter SK, Heggen V, et al. A program encouraging early defibrillation results in improved in-hospital resuscitation efficacy. $J$ Am Coll Cardiol 2004;44:846-52

8 Mattei LC, McKay U, Lepper MW, Soar J. Do nurses and physiotherapists require training to use an automated external defibrillator? Resuscitation 2002;53:277-80

9 Kerber RE, Martins JB, Kelly KJ, et al. Self-adhesive preapplied electrode pads for defibrillation and cardioversion. J Am Coll Cardiol 1984;3:815-20

10 Deakin C, McLaren R, Petley G, Clewlow F, Dalrymple-Hay M. A comparison of transthoracic impedance using standard defibrillation paddles and self-adhesive defibrillation pads. Resuscitation 2001;39:43-6

11 Walcott G,, Melnick S, Chapman F, Jones J, Smith W, Ideker R. Relative efficacy of monophasic and biphasic waveforms for transthoracic defibrillation after short and long durations of ventricular fibrillation. Circulation 1998;98:2210-15

12 Torok R, Till J. Biphasic or monophasic defibrillation for adult ventricular fibrillation. Emerg Med J 2003;20:464-5

13 Lermann B, Deale O. Relation between transcardiac and transthoracic current during defibrillation. Circ Res 1990;67:1420-6

14 Goktekin O, Melek M, Gorenek B, et al. Cardiac troponin T and cardiac enzymes after external transthoracic cardioversion of ventricular arrhythmias in patients with coronary artery disease. Chest 2002;122:2050-4

15 Walcott GP, Killingsworth CR, Ideker RE. Do clinically relevant transthoracic defibrillation energies cause myocardial damage and dysfunction? Resuscitation 2003;59:59-70

16 Kerber R, Kouba C, Martins J, et al. Advance prediction of transthoracic impedance in human defibrillation and cardioversion: importance of impedance in determining success of low energy shocks. Circulation 1984;70:303-8
17 Ewy G. Electrical therapy for cardiovascular emergencies. Circulation 1986;74:111-16

18 Dalzell G, Cunningham S, Anderson J, Asgey A. Electrode pad size, transthoracic impedance and success of external ventricular defibrillation. Am J Cardiol 1989;64:741-4

19 Dalzell G, Adgey A. Determinants of successful transthoracic defibrillation and outcome in ventricular fibrillation. Br Heart J 1991; 65:311-16

20 Caterine MR, Yoerger DM, Spencer KT. Effect of electrode position and gel-application technique on predicted transcardiac current during transthoracic defibrillation. Ann Emerg Med 1997;29:588-95

21 Kerber RE, Grayzel J, Hoyt R. Transthoracic resistance in human defibrillation: influence of body weight, chest size, serial shocks, paddle size and paddle contact pressure. Circulation 1981;63:676-82

22 Heames R, Sado D, Deakin C. Do doctors position defibrillation pads correctly? BMJ 2001;322:1393-4

23 Nurmi J, Rosenberg P, Castren M. Adherence to guidelines when positioning the defibrillation electrodes. Resuscitation 2004;61:143-7

24 Deakin CD, Sado D, Petley GW, Clewlow F. Is the orientation of the apical defibrillation paddle of importance during manual external defibrillation? Resuscitation 2003;56:15-18

25 Deakin C, Petley G, Cardan E, Clewlow F. Does paddle force applied during defibrillation meet advanced life support guidelines of the European Resuscitation Council? Resuscitation 2001;48:301-3

26 Sirna S, Ferguson D, Charbonnier F, Kerber R. Factors affecting transthoracic impedance during electrical cardioversion. Am J Cardiol 1988;62:1048-52

27 Guidelines for advanced life support. Resuscitation 1992;24:111-21

28 Sado D, Deakin CD, Petley GW, Clewlow F. Are European Resuscitation Council recommendations for paddle force achievable during defibrillation? Resuscitation 2001;51:287-90

29 Deakin CD, Sado D, Petley GW, Clewlow F. Determining the optimal paddle force for external defibrillation. Am J Cardiol 2002; 90:812-13

30 Deakin CD, Sado D, Petley GW, Clewlow F. Differential contribution of skin impedance and thoracic volume to transthoracic impedance during external defibrillation. Resuscitation 2004;60:171-4

31 Persse D, Dzwonczyk R, Brown C. Effect of application of force to self-adhesive defibrillator pads on transthoracic electrical impedance and countershock success. Ann Emerg Med 1999;34:129-33

32 Bissing J, Kerber R. Effect of shaving the chest of hirsute subjects on transthoracic impedance to self-adhesive defibrillation electrode pads. Am J Cardiol 2000;86:587-9

33 Sado D, Deakin CD, Petley GW, Clewlow F. Comparison of the effects of removal of chest hair with not doing so before external defibrillation on transthoracic impedance. Am J Cardiol 2004;93: 98-100 